\title{
Domain Name and Its Protection in India
}

\author{
Sukrut Deo, Sapna Deo
}

\begin{abstract}
The present article deals with the concept of domain name, its protection and conflicts arising out of malafide registration of the same. Before proceeding further, it is important to give a brief on what domain names are. A domain name is an actual name given to an Internet Protocol and has every qualification of identification. Since Internet protocols are complex combination of alpha numeric values, the domain names makes the identification process of a network easy to remember. For example, remembering 'humans' is easier than 'homo sapiens' and convenient also. Similarly remembering 'www.google.com' is easier than '64.233.191.255'. In later part of the research registration of domain names have been discussed in detail. In case of use of such registered domain name by third party unauthorizedly will amount to offence. The researcher has further thrown light on conflicts arising out of such unauthorized use and the judicial pronouncements towards the same. At the end various findings and suggestions regarding better dispute resolution system has been discussed.
\end{abstract}

Keywords: Domain name, Registrar, Registrant, TLD, WHOIS, ICANN.

\section{INTRODUCTION}

The trend of communication over the years has been changed rapidly since the emergence of computer technology. The invention of internet has replaced the old mode of communication by emails and media messages. A person sitting in one part of the world can easily connect to another in another part of world through once click over internet. Finding is not limited to communication but also seeking information is just a click away. All the businesses, educational and other institutes are accessible and reachable through the fast growing trend of internet.

Just like humans are given a name after their birth to make their identification easier, domain names also works the same way for internet protocol system. It is nothing but the name of the site. It is the addresses of the website which is user friendly and helps to identify the site so as to make masses connect to the internet. In USA the Lanham Act defines a domain name as:

Any alphanumeric designation which is registered with or assigned by any domain name registrar, domain name registry, or other domain name registration authority as part of an electronic address on the Internet. [1]

Now a days it is well recognizable by everyone that the "internet is not a physical or tangible entity, but rather a giant communications utilities, no single person, commercial or government entity controls the operation of the internet. [3] It "exists and functions as a result of the fact that hundreds of separate operators ....independently decided to use common data transfer protocols to exchange communications and information." [4]

While sharing or transferring any data or communication the network relies on particular standards and protocols. For assessing the internet each computer has a unique internet protocol address (IP). The IP address compromises of four groups of numbers separated by a decimal point. It is inconvenient to communicate through the IP address as it being in a numerical form which makes it tough to remember all the time. To the rescue we have a domain name which is specific and unique. Unlike IP address the domain name is separated by a "dot". For example ' 155.3 .65 .8 ' is an IP address whereas 'itsinternet.com' is a domain name.

The person who chooses the domain name is a registrant, and he himself chooses the name. The domain name has a length limit of 255 characters with up to 63 characters for each string. By domain name on the web which is a part of Uniform Recourse Locator (URL) informs a Domain Name Server (DNS) whether and where to transfer a request for a webpage.

A domain name includes the global endings that can be registered by anyone anywhere in the world, such as: - .org, .net, .com. In some countries they have unrestricted registrations like the United Kingdom (.co.uk.) etc.

There is a chance while selecting a domain name that other person might have registered the name that you have chosen for yourself. It is always a first come first thing for choosing a domain name. As far as corporate view is concerned it happen that some people might use your domain name in a bad faith so as to infringe your established trademark which is also termed as cyber squatting. Recovery of names is possible and not that costly but it is better to get the domain name register on the first come basis.

\section{METHODOLOGY}

The methodology opted by the researcher is "doctrinal". Such Doctrinal legal research has been carried out through following sources: Primary Sources such as International Treaties, Covenants and Conventions; Constitutional Provisions; Information Technology Act, 2000; Trademarks network which interconnects innumerable smaller groups of linked computer networks." [2] Unlike other
Revised Version Manuscript Received on July 10, 2019.

Mr. Sukrut Deo, Assistant Professor, Bharati Vidyapeeth (Deemed to be)University, NEW Law College, Pune, India.(e-mail: sukrutdeo29@gmail.com)

Dr. Sapna Deo, Assistant Professor, Bharati Vidyapeeth (Deemed to be)University, NEW Law College, Pune, India.(e-mail: sapna.deo@nlc.bvdu.in) 
Act, 1999; Copyrights Act, 1957; ICANN, WIPO, UNDRP etc.; Reported decisions of the courts and Secondary Sources such as Commentaries and reference books; Journals; Magazines; Newspaper articles; Official Statistics; Internet sources.

\section{FINDINGS}

\section{Getting Registered}

The Internet Corporation for Assigned Names and Numbers (ICANN), the organization charged with overseeing the name and numbers systems of the internet, accredited domain name registrars to delegate the right to use a domain name. The responsibility of maintaining data base of names registered is of the registry. Additionally, a sponsoring organization, the TLD Registry maintains and serves technically each top level domain (TLD). After receiving the information from each domain name receiving registrar, the registry publishes that information using a special service protocol WHOIS. The authorized users of a domain are known as "registrants" or "domain holders". The registry maintains the relationship between the registrants and the registrars.

The complete list of TLD registries is published by the ICANN and one can obtain information pertaining to registrant of a domain name in the WHOIS maintained by various registrars. For the convenience of creating space for new entrants the registrar separates the domain as per their key roles. Such as administrative contact who has a highest level of control over a domain and manages management level of information as to contact information, postal address, name of record etc., of the registrant. Then the technical contact manages the configurations of the domain name and maintaining domain zone records. The billing contact manages the person receiving invoices from the registrant and payment of applicable fees. The name server hosts a domain's resource record.

\section{Types of Domain Name}

Following are the few different types of domain names:

\section{TLD (Top Level Domains)}

TLD's are the highest level of the domain in the structure of the internet. Few of the TLD's are as follows:-

\section{ccTLD (Country Code Top Level Domain)}

it is the category of domain which shows the name of the country. It has a two letter country code indicating where it has been registered.

For instance -

$<$. uk $>$ for United Kingdom

$<. a u>$ for Australia

$<$.in $>$ for India

$<$.fr $>$ for France

$<$.ca> for Canada

\section{gTLD (Generic Top Level Domain)}

the well known generic top level domain are-

$<. c o m>-$ this is for commercial purpose aiming profit.

$<$. org>- these are used by nonprofit organizations main purpose being charity and public awareness. <.net>- the network organizations and internet infrastructure businesses use this.

$<. e d u>-$ this category is used by the educational institutes.

$<$.gov >- this is used by the government agencies.

$<$.mil >- this is used by the military users.

$<$.int >- this is for the international organizations.

IDN ccTLD - internationalized country code top-level domains

This is a top level name with a specifically encoded format which allows it to be getting displayed in special characters.

\section{Second level}

Below the TLD it comes directly, for example..com.au.

\section{Third level}

And below the second level comes the third level, for example..domainregistration.com.au.

There's a slight and confusing difference between third level and second level for instance rediffmail.com is considered a second level domain and rediffmail.com.au would be classified as a third level.

\section{Sub domain}

This is a part of a higher ranked domain name for instance: example.domainregistrartin.com.au.

\section{Disputes Pertaining to Domain Names}

In today's competitive world everyone wants to be in the race and out way each other. Many biggies companies have found a reputation and success which other competitors might try to hamper or envy. As it's a first come first get thing as far as domain name is concern, a name so lucrative that a company wanted to use for itself but already being taken by another company and that company doing pretty well in the market might lead the company to misuse that name or similar for its own establishment. This leads to infringement of such established trademark. Domain names and trademarks are closely connected. When someone uses domain name similar to others trademarks for gaining profit or selling, this act is known as 'Cybersqatting'.

\section{RESULTS AND DISCUSSION}

After undergoing the research it is clear that adopting same or similar domain name as part of brand name or vice versa is an offence. These offences are often termed as 'cybersquatting'. The remedies towards the same have been covered under the provisions of Indian Trademarks Act, 1999 under the laws of passing off. Many judicial pronouncements have been done on the base of such laws. The first case pertaining to cybersqatting in India was Yahoo Inc. v. Akash Arora[5], in this case the defendant launched an identical website to that of plaintiff's renowned Yahoo.Inc and named and registered his website as YahooIndia.com. It was observed by the court that, "it was an effort to trade on the fame of yahoo's trademark. A domain name registrant does not obtain any legal right to use that particular domain name simply because he has registered the domain name, he could 
be liable for trademark infringement".

In Rediff Communications Ltd v. Cyberbooth [6] the plaintiff had registered <rediff.com> as its domain name whereas the defendant his domain name as <radiff.com>. The defendant contended that it has coined the words as it has a different sense for internet users and in no way it is deceptive as the internet users are a skilled persons. The court observed that the value and importance of a domain name is like a corporate asset of a company. The court gave decision in favor of the plaintiff.

Satyam Infoway Ltd v. Siffynet Solutions (P)[7], in this case the M/s Satyam Infoway Limited was incorporated in 1995 with several registered domains namely, www.sifynet, www.sifymail.com etc. with ICANN and WIPO. The respondent started carrying out the business of internet marketing under the domain names www.sifynet.co and siffynet.com, and claimed that he had obtained it from ICANN. When the appellant came to know about the use of word siffy by the respondent, he served notice on defendant to stop using the name for its business and also to transfer the domain names to the appellant. The respondent refused. The appellant filed a civil suit and sorted injunction. The civil court granted injunction and gave order in favor of the appellant stating that it's been using the name since before the defendant and are a very established name, it may cause confusion in the minds of the costumers and therefore restrained the defendant from using the domain name.

Further the respondent preferred an appeal before the High Court. The High Court granted an interim stay over the order of Civil Court. The said order was the subject matter of this appeal. The High Court was of the view that merely on the ground that the appellant was using the name firstly should not be taken into consideration without considering the convenience lay. Agreed that the appellant had earned a goodwill and reputation in the name of sify but it was not based on consideration of necessary factors. Considering the facts presented by the defendant it was found out that the defendant is into a completely different business that is done by the appellant. Thus there was no question of the consumers misled, misguided or confused. Similarly lot of investment was gone of defendant for establishing that business and that it had enrolled 50,000 members already. It was held that the respondent would suffer a great hardship, inconvenience and irreparable injury if they'll have to refrain from doing the said business. On other hand since the appellant has a separate trade name namely, satyam infoways, no hardship or injury would be caused to the appellant if the order of injunction was not granted.

The Apex court observed: "this brings us to the merit of the dispute between the parties. As we have already said, a passing off action is based on the goodwill that a trader has in his name unlike an action for infringement of a trade mark where a trader's right is based on property in the name as such. Therefore, unless goodwill can be established by the appellant by showing that the public associates the name "sify" with the services provided by the appellant, it cannot succeed."

The apex court came to the conclusion that the respondent was seeking to cash in on the appellants reputation as a provider of services on the internet. in view of findings, albeit prima facie on the dishonest adoption of the appellants trade name by the respondent, the investments made by the appellant in connection with the trade name, and the public association of the trade name 'Sify' with the appellant, the appellant was entitled to the relief it claimed. A different conclusion might be arrived at if evidence $t$ the contrary was adduced at the trial. But at thisS stage and on the material before the Court, the Apex Court was of the view that the conclusion of the High Court to the contrary was unwarranted. The appeal was accordingly allowed. The decision of High Court was set aside and that of the City Civil Court affirmed. [8]

\section{CONCLUSION}

As apparent from the above discussion a domain name is not only a name that distinct an entity from others, it is also a source that gives out reputation and goodwill which in no cases any entity can infringe by using alike domain name. It is an exclusive right of the registrant to use his domain name. This right of the registrant is thus protected by the law and time and again the judicial mechanism has been giving fair justice to the person or entity seeking it. Thus, the domain name is well secured and protected by the law.

\section{REFERENCES}

1. 15 U.S.C. 1127 (Lanham Act 45).

2. Am. Civil Liberties Union v. Reno, 929 F.Supp. 824,830 (E.D.Pa.),affd,521U.S.844(1977).

3. Id.at 832.

4. Id.

5. I.P.L.R.1999 April 96:1999 PTC(19)201.

6. A.I.R.2000 Bom.27.

7. (2004) 19 ILD 30(SC).

8. R.P. Kataria, S.K.P.Srinivas," Cyber Crimes Law Practice and Procedure", Orient Publishing Company2013, pp.271-277.

9. Sarda, M., Deshpande, B., Dharm, J., Dhere, V., Different aspects of environmental laws , International Journal of Recent Technology and Engineering, 2019

10.Sarda, M., Deshpande, B., Deo, S., Karanjkar, A comparative study on Maslow's theory and Indian Ashrama system, International Journal of Innovative Technology and Exploring Engineering ,2018

11.Sarda, M., Deshpande, B., Shringarpure, S., Smart city Use of technology and the needed labor reforms, International Journal of Innovative Technology and Exploring Engineering ,2018 